\title{
Asociaciones de pacientes
}

\section{Patient associations}

Invitamos a Ricarte Soto a editorializar este número de la Revista, por su trabajo preparatorio y liderazgo en la marcha de los enfermos del 4 de mayo pasado.

Queríamos conocer por su mano la reflexión suscitada por este acontecimiento. Publicamos el texto que tuvo la gentileza de remitirnos y que agradecemos expresamente.

A fines de ese mismo mes, la asamblea ciudadana de Quellón cortó el camino que une Castro con esa ciudad por demandas respecto de la atención de salud comunal. El camino fue despejado, tras un acuerdo de 25 puntos, firmado con el Ministro de Salud el 30 de mayo.

Este mismo mes de mayo tuvimos la oportunidad de comentar con estudiantes y docentes de la carrera de enfermería de la Universidad de Concepción, la película How to survive to a plague, del Director David France, reconocida como una de los mejores documentales norteamericanos de 2012. Allí se narra la organización y movilización de pacientes con SIDA en Estados Unidos, para proponer investigación, ensayos clínicos y regulaciones desde el inicio de la pandemia en los años 80. Un animado diálogo nos retuvo hasta pasadas las 20 horas el día 24 en el aula magna de la Facultad de Medicina.

Las asociaciones de pacientes tienen larga data. Pero la dimensión que actualmente han tomado, debatiendo al interior de los protocolos acerca de reglas técnicamente fundadas, no pueden seguir siendo abordadas usando las clásicas fórmulas de participación social. Ni tampoco cooptándolos con recursos. Mucho menos considerándolos un frente beligerante al cual aproximarse una vez que las presiones han desbordado todo cauce. Uno de los méritos que reconocemos a la Reforma es la centralidad que asumió el desarrollo tecno-científico y la medicina clínica como orientación del sector público, que ha potenciado esta animación de los pacientes.

Las interrogantes de Walter Lippman (1925) y de John Dewey (1927) acerca de lo público, de sus problemas, de su aparición fantasmal y sus vinculaciones con

Yuri Carvajal Escuela de Salud Pública, Facultad de Medicina, Universidad de Chile. ycarvajal@med.uchile.cl la democracia, son fuentes valiosas para un acercamiento a estos nuevos hechos, desde una disciplina que adjetiva ese sustantivo en su propio nombre.

Lippman y Dewey debatieron la movilidad y fugacidad de los públicos. Steve Epstein señala hoy la borrosidad de los límites de las asociaciones de pacientes. 
Aún más, desde la perspectiva de Estudios Sociales de Ciencia, se pregunta por las condiciones de desarrollo tecno-científico implicadas en este surgimiento de pacientes y movimientos, de qué manera aspectos específicos de las enfermedades afectan su despliegue y qué tipos de saber emplean esos grupos de pacientes para ejecutar sus acciones.

Las experiencias nacionales con organizaciones de pacientes requieren mayor esfuerzo de Salud Pública para responder algunas de estas inquietudes, además de las provenientes de las mismas asociaciones, así como las que surjan del mismo quehacer. Las asociaciones de pacientes, su actividad pública y sus esfuerzos, no son sólo un desafío temático para la investigación, sino la oportunidad para generar o traducir nuevos métodos, nuevas concepciones de lo que es una actividad de campo o una salida a terreno, en suma, para ser parte de una experimentación colectiva. 